\title{
Comparisons Study of Phosphate Removal in Unaerated and Aerated High Calcium Steel Slag Filter System of Different pH Feed
}

\author{
Siti Zu Nurain Ahmad ${ }^{1}$, Hamdan R. ${ }^{1,{ }^{*}}$,Wan Afnizan Wan Mohamed $^{2}$,N. Othman ${ }^{2}$, Nur \\ Shaylinda Mohd Zin ${ }^{2}$, S. Musa ${ }^{2}$ \\ ${ }^{1}$ Department of Civil Engineering Technology, Faculty of Engineering Technology, UniversitiTun \\ Hussein Onn Malaysia, 86400 Parit Raja, BatuPahat, Johor, Malaysia \\ ${ }^{2}$ Department of Water and Environmental Engineering, Faculty of Civil and Environmental \\ Engineering, UniversitiTun Hussein Onn Malaysia, 86400 Parit Raja, BatuPahat, Johor, Malaysia
}

\begin{abstract}
Excess phosphorus in water body will lead to eutrophication. This study investigated the phosphate removal efficiencies of unaerated and aerated filter systems using high composition of Calcium $(\mathrm{Ca})$ steel slag as the filter media at different $\mathrm{pH}$ values of the wastewater influents. Lab-scale filters were developed using $25 \mathrm{mg} / \mathrm{L}$ synthetic wastewater and weekly sampling was done to monitor the phosphate removal efficiencies together with the concentration of metals (Calcium (Ca) and Magnesium $(\mathrm{Mg})$. The results show that both unaerated and aerated systems have excellent phosphate removal efficiency at all acidic, neutral and alkaline $\mathrm{pH}$ feed, though unaerated systems removed slightly better compared to aerated systems; $76-98 \%$ and $69-97 \%$ respectively. The dominant phosphate removal mechanism for aerated systems was adsorption, meanwhilefor unaerated systems; both adsorption and precipitation for acidic and neutral $\mathrm{pH}$, whileprecipitation was more dominant at basic $\mathrm{pH}$. The performance of unaerated systems are slightly better compared to aerated systems, however, aerated systems are recommended to be applied when simultaneous removal of nutrients (phosphorus and nitrogen) are concerned.
\end{abstract}

\section{Introduction}

There is a dual concern regarding nutrients, since they contribute to unfavorable health and environmental effects, thus their control is imperative, but the same nutrients are essential for the performance of the natural biological treatment systems[1].The most significant effect of phosphorus in the environment is eutrophication or algal bloom. This process will promote a great deal of plant and animal biomass production, which eventually leads to succession in aquatic ecosystems [2]. Since 1950s, development of technologies of phosphorus removal has been studied in response to the issue of eutrophication. Since then,

*Correspondingauthor: rafidahh@uthm.edu.my 
scientists had realized the need to reduce the amount of phosphorus allowed to enter the water body [3].

Nowadays, natural wastewater treatment process such as waste stabilization ponds (WSP), constructed wetlands $(\mathrm{CW})$ and rock filters $(\mathrm{RF})$ are very outstanding alternatives for phosphorus removal.. The utilization of low-cost and easily available materials as the filter media has been widely demonstrated by previous studies for their reliability and contribution in the removal of phosphate including fly ash [4], limestone[5], iron oxide tailings [6], blast furnace slag [7], basic oxygen furnace slag and electric arc furnace slag [8].

Steel slag has shown great phosphate removal efficiency as filter media for RF. One of the types of steel slag is an electric arc furnace (EAF) slag which is a by-product of melting recycled scrap in an electric arc furnace during the steel-making [9]. The significant contribution of steel slag in phosphate removal is generally due to high concentration of metal (Ca, Fe, Al, Mg) oxides [10]. However, the chemical compositions of all steel slags are not the same due to the variations in the grade of steel products and type of furnaces used during the process of steel-making [10]. Nevertheless, adsorption and precipitation with metal oxides are the main phosphate removal mechanisms in rock filters [11].

Performance of phosphorus removal was affectedby parameters include $\mathrm{pH}$, temperature, concentration of metallic salts, HRTv and many more [12]. Of all these, $\mathrm{pH}$ values of the influents are known to contribute significant effects on phosphorus removal. The mechanism of phosphate removal can be differentdue to the different chemical composition of the steel slag. Very high percentage of $\mathrm{CaO}$ of the steel slag providesa significant rate of dissolution of $\mathrm{Ca}$, causing formation of $\mathrm{Ca}$ phosphate, which were formed at high $\mathrm{pH}$ value and the precipitation dominates the removal mechanism. On the other hand, a high percentage of $\mathrm{Fe}_{2} \mathrm{O}_{3}$ of the steel slag prefers adsorption onto $\mathrm{Fe}$ oxides forthe phosphate removal mechanism at acidic and neutral $\mathrm{pH}$ ranges [13]. Besides that, precipitation might occur resulting from the dissolution of Fe from Fe oxides [14]. This is due to thefact that $\mathrm{Fe}$ ions tend to dissolve at acidic condition, which can be related to the precipitation of $\mathrm{Fe}$ phosphates meanwhile $\mathrm{Ca}$ ions tend to dissolve at basic condition which was related to $\mathrm{Ca}$ phosphate formation.

Unaerated system and aerated system differ in the introduction of oxygen into the systems during the aeration process. Aerated system provides aerobic condition to the system during the aeration process. Under aerobic conditions, $\mathrm{Ca}$ and $\mathrm{Al}$ adsorb onto the surface of adsorbent which can be the adsorption site for phosphate removal whereas phosphate are precipitated out with Fe ions [15]. Besides that, high dissolved oxygen in aerated conditions causes much more carbon dioxide to be stripped to the atmosphere thus produce little carbonic acid. This results in the increase in $\mathrm{pH}$ levels in the system [12]. Therefore, this study was carried out to compare the difference performance of aerated and unaerated high $\mathrm{Ca}$ steel slag systems at different $\mathrm{pH}$ values for its phosphate removal efficiency.

\section{Experimental}

\subsection{Materials}

The high Ca electric arc furnace (EAF) steel slag was obtained from Pasir Gudang, Johor, Malaysia. The steel slag was characterizedusing X-ray Fluorescence Spectroscopy (XRF) to obtain its chemical composition. The XRF results obtained were shown in Table 1. For preparation of XRF samples, the solid steel slag was crushed manually using a hammer and the crushed samples were collected and sieved through a 63 micrometer test sieve (British 
Standard sieve BS410/1986) using a shaker, Endecotts Lombard Rd. London, model Sw193BR, England. Meanwhile, the steel slag samples in the range of sizes of $9.5 \mathrm{~mm}$ to 20 $\mathrm{mm}$ were accepted for use as filter mediain the column study. The samplespretreatmentincludewashing up twice the steel slag with tap water followed by distilled water before they were dried up in the oven for 24 hours at $105^{\circ} \mathrm{C}$.

Table 1.The XRF Results for Chemical Composition of Steel Slag

\begin{tabular}{|c|c|}
\hline $\begin{array}{c}\text { Compoun } \\
\text { ds }\end{array}$ & $\begin{array}{c}\text { Percentage } \\
\text { (\%) }\end{array}$ \\
\hline $\mathrm{CaO}$ & 49.5 \\
\hline $\mathrm{SiO}_{2}$ & 18 \\
\hline $\mathrm{MgO}$ & 4.32 \\
\hline $\mathrm{SO}_{3}$ & 2.58 \\
\hline $\mathrm{Al}_{2} \mathrm{O}_{3}$ & 2.23 \\
\hline $\mathrm{Fe}_{2} \mathrm{O}_{3}$ & 1.64 \\
\hline $\mathrm{MnO}_{2}$ & 0.38 \\
\hline $\mathrm{TiO}_{2}$ & 0.22 \\
\hline
\end{tabular}

\subsection{Filter Column Study}

To investigate the differences between unaerated and aerated systems on the phosphate removal efficiency using high $\mathrm{Ca}$ steel slag as the adsorbents, lab-scale vertical column filters study was developed. Twelve column filters with different $\mathrm{pH}$ values of the influents $(\mathrm{pH} \mathrm{3,} \mathrm{5,} \mathrm{7,} \mathrm{9,} 11$ and Control) for unaerated and aerated systems with the inner diameter of $150 \mathrm{~mm}, 6 \mathrm{~mm}$ thickness and total height of $400 \mathrm{~mm}$ made from Perspex materials were set up as shown in Fig. 1. The column filters for Control systems used distilled water as the feed. The $\mathrm{pH}$ values of all different $\mathrm{pH}$ systems were adjusted using $2 \mathrm{~N} \mathrm{NaOH}$ and $2 \mathrm{~N}$ $\mathrm{H}_{2} \mathrm{SO}_{4}$.

The $\mathrm{pH}$ values were monitored and adjusted frequently in order to minimize its fluctuation, especially for very low and very high $\mathrm{pH}$ values. HANNA HI-99310 portable $\mathrm{pH}$ meter was used to measure the $\mathrm{pH}$ and temperature. The influent was set to $25 \mathrm{mg} / \mathrm{L}$ synthetic wastewater (typical concentration range of phosphorus in wastewater in Malaysia) which was prepared by dissolving $\mathrm{KH}_{2} \mathrm{PO}_{4}$ salts (as the phosphate source) into distilled water. Synthetic wastewater feed was flowed via gravity from the influent tank located at the higher level and connected to the influent point which was located at the bottom of each column filters. The effluents of the samples were collected at the upper layer valves of each column filter. The hydraulic loading rate (HLR) used for the systems was set at 0.60 $\mathrm{m}^{3} / \mathrm{m}^{3}$.d following Johnson [15].

Meanwhile, aerated system was developed by connecting the tube from the air pump to the base of the column filters. The column filters were continuously fed with synthetic wastewater andweekly sampling was done for the influents and the effluents of each filter to test for $\mathrm{pH}$, orthophosphate concentration and metals $(\mathrm{Ca}$ and $\mathrm{Mg}$ ) concentration. 


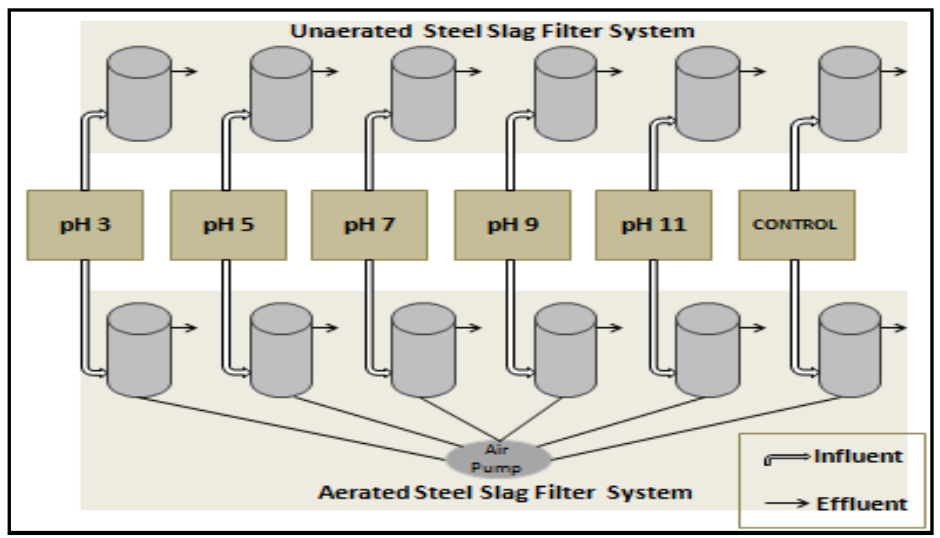

Fig. 1.Schematic diagram of lab-scale vertical steel slag column filters system

\subsection{Analysis Methods}

The samples were analyzed for the concentration of orthophosphate following the ammonium molybdatespectrometric method using WESTCO Discrete Analyzer, model Smartchem 200, France. The phosphate removal efficiency was obtained by determining the removal percentage of the phosphate. Meanwhile, the concentration of $\mathrm{Ca}$ ions and $\mathrm{Mg}$ ions were analyzedfollowing3111B Standard Methods for Examination of Water and Wastewater; atomic absorption spectrometric (AAS) method; [10] using model Perkin Elmer AAnalyst 100.

\section{Results and Discussion}

\subsection{Phosphate removal efficiencies of unaerated and aerated high Calcium steel slag filter systems}

Fig. 2 (a-e) illustrates the phosphate removal efficiencies of high Ca steel slag for unaerated and aerated filters at $\mathrm{pH}$ values of 3, 5, 7, 9 and 11 respectively. Generally, similar trends can be detected for all of the different $\mathrm{pH}$ systems; unaerated systems performances were slightly better compared to aerated systems. Nevertheless, aerated systems' performance can still be considered as efficient in removing phosphate since their percentage removal is around $69-97 \%$ while unaerated systems removed $76-98 \%$.

Fig. 2(a) shows the removal efficiency of phosphate at $\mathrm{pH} 3$ where very similar trends of phosphate removal efficiencies were shown with slightly better performance of unaerated $\mathrm{pH} 3$ system compared to aerated $\mathrm{pH} 3$ systems. Both systems showed excellent removal of phosphate between $77-97 \%$. The highest percentage removal was shown during day 21 sampling at $97.9 \%$. Meanwhile, systems at $\mathrm{pH} 5$ also showed similar behaviour which can be seen in Fig. 2(b); highest removal for the first four weeks then started to decline; 77-97\% and $74-97 \%$ for unaerated and aerated system respectively.

In Fig. 2(c), it can be seen that the removal efficiency of phosphate for unaereated $\mathrm{pH} 7$ system was $76-98 \%$ whereas aerated $\mathrm{pH} 7$ system was $71-95 \%$. Unaerated system performed slightly better in removing phosphate compared to aerated system. Same goes to pH 9 and pH 11 systems, unaerated systems perform better; $77-97 \%$ for $\mathrm{pH} 9$ and $76-97 \%$ for $\mathrm{pH} 11$. The aerated systems followed closely behind; $69-96 \%$ for $\mathrm{pH} 9$ and $67-91 \%$ for $\mathrm{pH} 11$. 


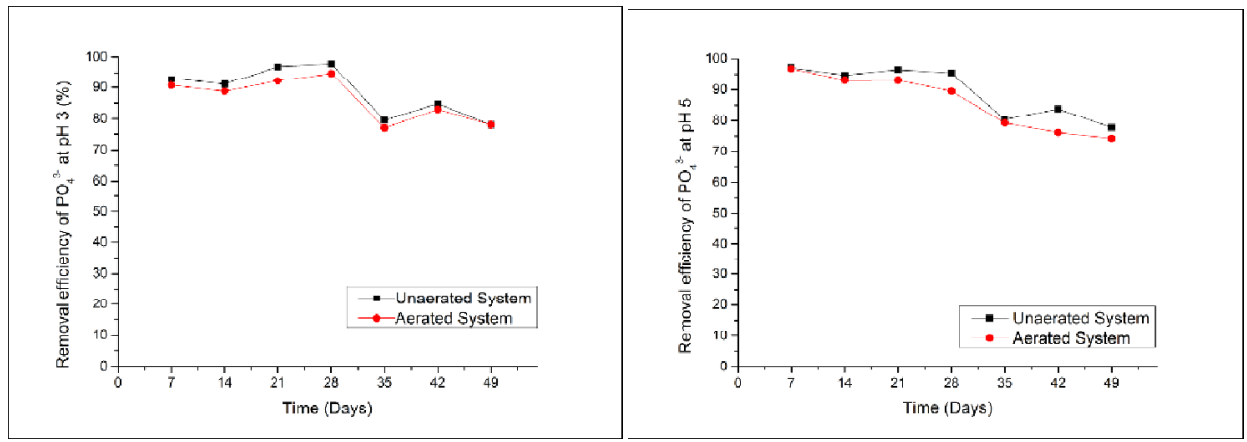

(a)

(b)

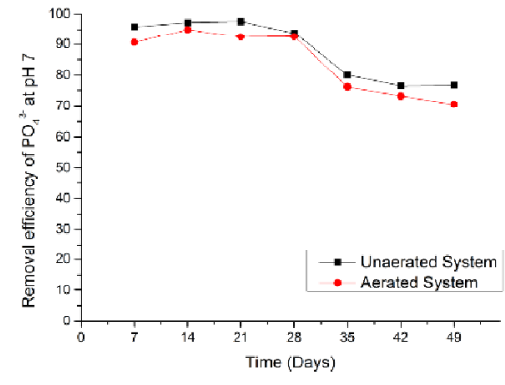

(c)

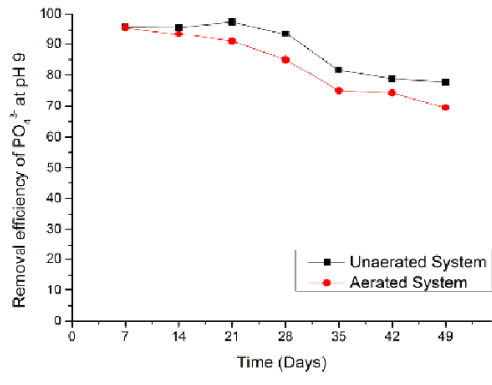

(d)

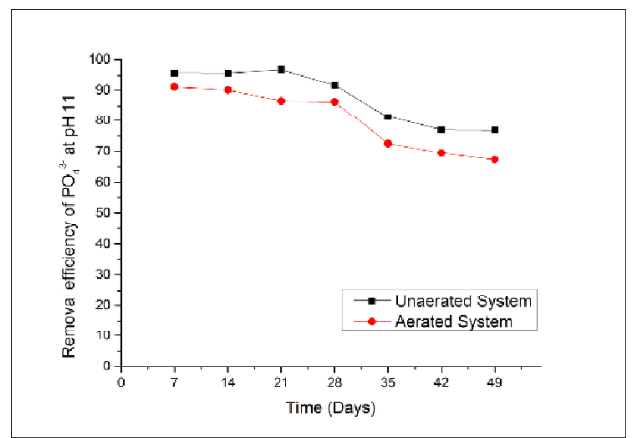

(e)

Fig. 2. (a-e) represents removal efficiency of phosphate from the filter systems of: (a) $\mathrm{pH} 3$ systems; (b) pH 5 systems; (c) pH 7 systems; (d) pH 9 systems; (e) pH 11 systems.

All of the systems illustrated that the phosphate removal efficiencies are the best during the first four weeks before they started to decrease slightly and then consistent. During the first four weeks, many surface sites for removal mechanism were available. Therefore, they performed the best. However, after that, the surface sites for reaction had decreased a little due to the precipitates formed as the results of the removal causing certain surface sites to be unavailable for further reaction. This is true for unaerated systems because the systems were not disturbed; no aeration which allowed precipitates to form. On the other hand, aerated systems did not show a significant amount of precipitates inside the filters though the removal of phosphate still happened. This indicated that the removal mechanism followed adsorption mechanism rather than precipitation. However, the sampling duration should be extended some more to see the exact trends following after. 
Overall, unaerated systems performed slightly better in phosphate removal compared to aerated systems. All of the different $\mathrm{pH}$ systems, either acidic, neutral or alkaline, has high phosphate removal efficiencyand this could be very advantageous in the removal of phosphate at different $\mathrm{pH}$ feed for wastewater treatment technology.

\subsection{The effects of $\mathrm{pH}$ related to the concentration of $\mathrm{Ca}$, and $\mathrm{Mg}$ ions in effluents and the phosphate removal mechanism}

Fig. 3(a-f) illustrated the concentration of $\mathrm{Ca}$ and $\mathrm{Mg}$ in effluents at $\mathrm{pH}$ values of 3, 5, 7, 9, 11 and Control for both unaerated and aerated systems. At pH 3 as shown in Fig. 3(a), concentrations of $\mathrm{Ca}$ in effluents are significantly greater in unaerated systems compared to aerated system. This showed that the significant role of $\mathrm{Ca}$ ions in the phosphate removal mechanism via precipitation for unaerated system.

Similar trends can be seen in pH 5, 7, 9 and Control systems as seen in Fig.3 (b), (c), (d) and (f) respectively. The concentration of $\mathrm{Ca}$ in unaerated systems was obviously greater compared to aerated systems. In unaerated systems, visible white precipitates formed could be seen especially at the inlet of the filters, which were thought to be Calcium-phosphate precipitates either hydroxyapatite (HAP) or its precursors. The amount of white precipitates formed was greater for basic $\mathrm{pH}$ systems ( $\mathrm{pH} 9$ and $\mathrm{pH} 11$ unaerated systems). This showed that the phosphate removal mechanism for unaerated systems followed both precipitation and adsorption mechanisms, only the significance of precipitation were greater and ruled the pathway at basic $\mathrm{pH}$ compared to acidic $\mathrm{pH}[14]$.

Meanwhile, aerated systems caused less concentration of $\mathrm{Ca}$ in effluents. This was actually contradicted to the assumptions made that aeration causes greater rate of dissolution of the metal ions inside the steel slag due to vibration. Physically, only a small amount of cloudy sludge can be seen in the filters and no visible white precipitates were formed. Nevertheless, their performance in removing phosphate was considered as excellent, comparable to unaerated systems. Therefore, adsorption might be more significant phosphate removal mechanism in aerated systems since no white precipitates were visible in the filters. The adsorption follows inner-sphere ligand exchange mechanism [15] where they reacted by forming monodentate and bidentate complexes which were determined by how they were coordinated [16].

Meanwhile, the concentrations of $\mathrm{Mg}$ are very small for all of the systems, less than 1 $\mathrm{mg} / \mathrm{L}$. Little can be obtained from here since the trends are very similar for both unaerated and aerated systems, with slightly higher concentration of $\mathrm{Mg}$ for unaerated systems. However, this shows that $\mathrm{Mg}$ ions have a less significant contribution compared to $\mathrm{Ca}$ ions in the removal of phosphate.

The performance of unaerated systems are slightly better compared to aerated systems. Nevertheless, since the importance of aeration is very crucial when removing nitrogen from wastewater; therefore when the desired results are to remove both nutrients simultaneously, therefore aerated systems' performance can be considered as an excellent choice. 


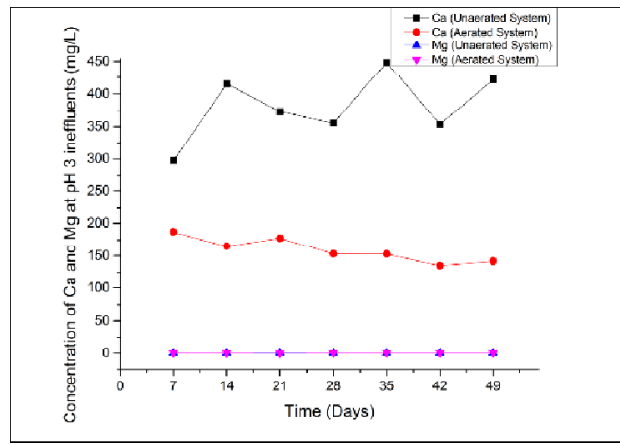

(a)

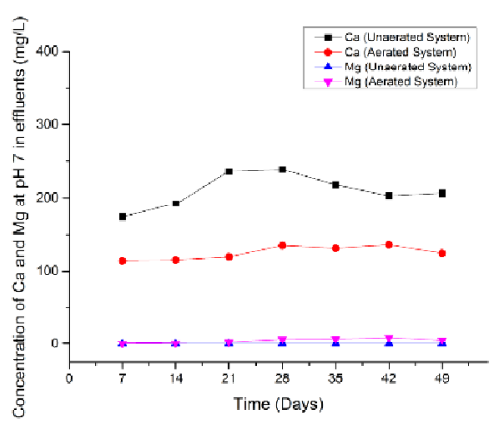

(c)

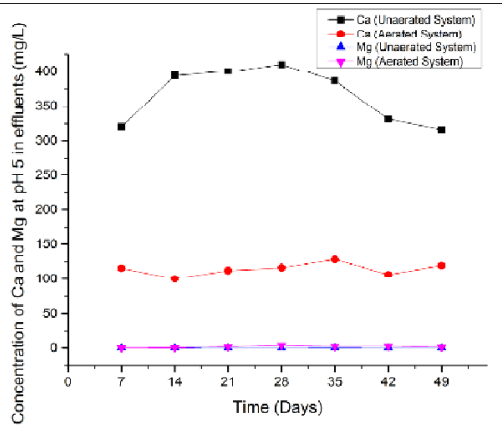

(b)

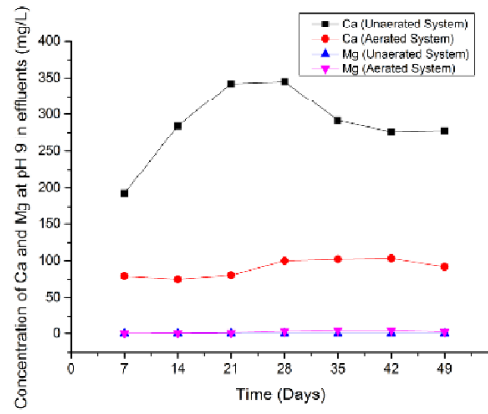

(d)

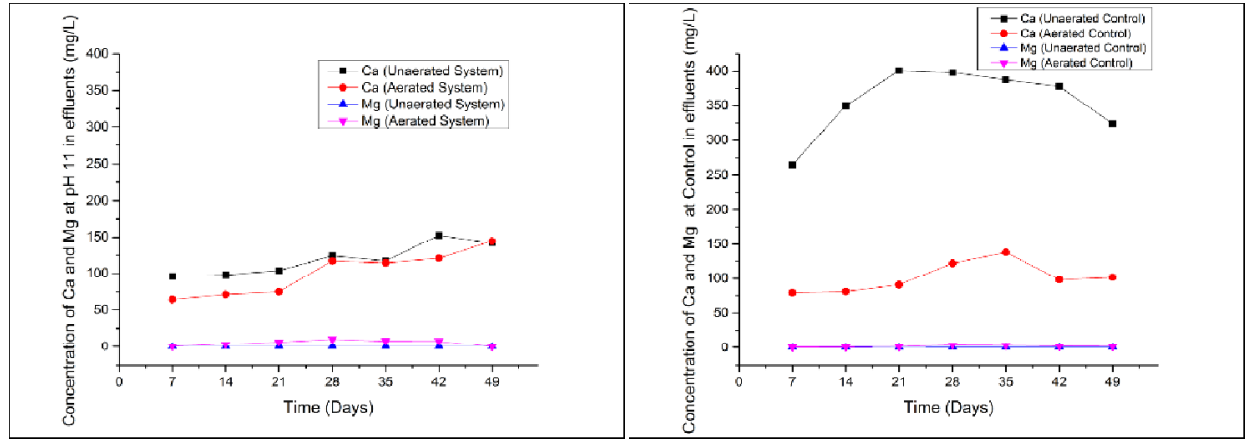

(e)

(f)

Fig. 3. (a-f) represents the concentration of $\mathrm{Ca}$ and $\mathrm{Mg}$ in effluents at systems of: (a) $\mathrm{pH} 3$ systems; (b) pH 5 systems; (c) pH 7 systems; (d) pH 9 systems; (e) pH 11 systems; (f) Control systems

\section{Conclusions}

This study showed that both unaerated and aerated, high Ca steel slag filter systems were very efficient in removing phosphate at all acidic, neutral and basic $\mathrm{pH}$ influents. The percentages of phosphate removal efficiency for unaerated systems were found to be around $76-98 \%$, while aerated systems removed $69-97 \%$ of phosphate. Ca concentrations in effluents are higher for unaerated systems compared to aerated systems, meanwhile $\mathrm{Mg}$ concentrations are similar for all the systems. The dominant phosphate removal mechanism 
followed adsorption for aerated systems and both adsorption and precipitation for unaerated systems; where at acidic and neutral $\mathrm{pH}$, both adsorption and precipitation ruled the mechanism, meanwhile at basic $\mathrm{pH}$, precipitation was more dominant.

We are grateful for the fundings provided by Ministry of Higher Education and University Tun Hussein Onn Malaysia; ERGS VOT.E031 and GPPS VOT U513.

\section{References}

[1] S.C. Reed, Nat.systems for waste management and treatment, 2nd ed. New York:McGraw-Hill,(1995)

[2] S. Manahan, Fundamentals of Enviro. Chem., 3rd ed. Boca Raton, Florida:Taylor\&Francis/CRC Press,(2009)

[3] G.K. Morse, S.W. Brett, J.A. Guy andJ.N.U. Lester, Review : Phosphorusremoval and recovery technologies. The Sci. of the Tot. Env., 212, 69-81,(1998)

[4] Y.Z. Li, C.J. Liu, Z.K.Luan, X.J. Peng, C.L. Zhu, Z.Y. Chen, Z.G. Zhang, J.H. Fan and Z.P. Jia, Phosphate RemovalFromAqueous Solution UsingRaw and ActivatedRedMud and Fly Ash. J. Hazard. Mater. 137, 374-383, (2006)

[5] L. Johansson-Westholm, Substrates for PhosphorusRemoval-potentialBenefits for Onsite WastewaterTreatement, Water Resources. 40(1), 23-36. (2006)

[6] I. Blanco, P. Molle, L. Miera, G. Ansola, Basic OxygenFurnaceSteelSlagAggregates for PhosphorusTreatment: Evaluation of ItsPotential Use as a Substrate in ConstructedWetlands, Water Research, 89, 355-365 (2016)

[7] C. Barca, C. Gerente, D. Meyer, F. Chazarenc, Y. Andres,Phosphate RemovalfromSynthetic and Real WastewaterUsingSteelSlagsProduced in Europe, Water Resources. 89, 1-6 (2012)

[8] C. Barca, S. Troesch, D. Meyer, P. Drissen, Y. Andres, F. Chazarenc, SteelSlagFilters to Upgrade PhosphorusRemoval in ConstructedWetlands: TwoYears of Field Experiments, Env. Sci. Tech.,47, 549-556 (2013)

[9] C. Barca, D. Meyer, M. Liira, P.Drissen, Y. Coemau, Y. Andres, F. Chazarenc, SteelSlagFilters to Upgrade PhosphorusRemoval in WastewaterTreatment Plants: RemovalMechanisms and Performance, Eco. Eng., 68, 214-222 (2014)

[10] R. Hamdan, D. Mara, Study of In-filterPhosphorusRemovalMechanisms in an Aerated Blast FurnaceSlag, Int. J. of Research in Eng. and Tech., 2(8), 130-136 (2013)

[11]C. Han, Z. Wang, W. Yang, Q. Wu, H. Yang, X. Xue, Effects of pH on PhosphorusRemovalCapacities of Basic OxygenFurnaceSlag, Eco. Eng.,89,1-6 (2016)

[12]P. Wifert, P.S. Kumar, L. Korving, G. Witkamp, M.C.M. Loodsrecht, The Relevance of Phosphorus and IronChemistry to the Recovery of PhosphorusfromWastewater: A Review, Env. Sci. and Tech., 49, $99400-9414$ (2015)

[13] M.Scholz, WetlandsSystems to Control UrbanRunoff, Elsevier, Oxford, United Kingdom, (2006)

[14]S.E. Johnson, R.H. Loeppert, Role of OrganicAcids I Phosphate MobilizationfromIronOxides, SoilSci. Soc. Am. J., 70, 222-234 (2006)

[15]B. Zhong, R. Stanforth, S. Wu, J.P. Chen, Proton Interaction in Phosphate Adsorption onto Goethite, J. of ColloidalInterfacialSci., 308, 40-48 (2007) 
[16]A. Klimeski, W.J. Chardon, E. Turtola, R. Uusitola, Potential and Limitations of Phosphate Retention Media in Water Protection: A Process-basedReview of Laboratory and Field-scale Tests, Agr. and Food Sci., 21, 206-223 (2012) 